Türkiye Jeoloji Bülteni
Geological Bulletin of Turkey
$60(2017) 557-568$
doi:10.25288/tjb.363822

\title{
Diyarbakır Havzasında İklim Üzerinde Etkili Olan Yer Şekilleri ve Litolojik Faktörlerin MODİS Uydu Görüntüsü Verileri İle İncelenmesi
}

Investigation the Effects of Landforms and Lithological Factors on the Climate in Diyarbakir Basin Using MODIS Satellite Data

\author{
Sabri Karadoğan' ${ }^{1}$, M. Tahir Kavak² (D) \\ ${ }^{1}$ Dicle Üniversitesi, Ziya Gökalp Eğitim Fakültesi, Coğrafya Eğitimi Anabilim Dal, Diyarbakır \\ ${ }^{2}$ Dicle Üniversitesi, Ziya Gökalp Ĕ̈itim Fakültesi, Fizik Eğitimi Anabilim Dalı, Diyarbakır
}

Geliş/Received : 21.08.2017 • Düzeltilmiş Metin Geliş/Revised Manuscript Received : 14.11.2017 • Kabul/Accepted : 16.11 .2017 • Bask1/Printed : 29.12 .2017 Araştırma Makalesi/Research Article Türkije Jeol. Bül. / Geol. Bull. Turkey

Öz: Yeryüzünde iklim üzerinde etkili olan faktörlerden biri de yer şekilleri ve kayaç özellikleridir. Yer şekilleri hava kütleleri önünde engel oluşturarak yoğuşma, bakı ve fön olaylarının oluşmasında etkili olur. Litolojik faktörler de farklı kayaçların güneş radyasyonunu farklı yansıtmaları (albedo) nedeniyle farklı yer ışımalarına, dolayısıyla yeryüzünün farklı bölgelerinin farklı ısınmasına neden olur. Bu çalışmada Diyarbakır havzasında söz konusu koşulların iklim üzerindeki etkisinin belirlenebilmesi amacıyla uzaktan algılama teknikleri ve verileri kullanılmıştır. $\mathrm{Bu}$ amaçla havzanın yüzey sıcaklığı verilerini elde etmek için TERRA uydusunun MODIS spektroradyometresine ait 7 Nisan 2010 tarihli gündüz ve gece görüntüleri elde edilmiştir. Yüzey sıcaklık verilerinden faydalanılarak yüzey sıcaklığı haritaları oluşturulmuş ve yüzey ağları modeli ile çakıştırılmıştır. Ayrıca baskın hava kütleleri ve farklı yeryüzü şekilleri dikkate alınarak oluşturulan kesit hatları boyunca hem gündüz hem de gece verileri üzerinden yüzey sıcaklığı değişim grafikleri oluşturulmuştur.

Yapılan çalışmalar sonucu hem litolojik faktörlerin, hem de baskın hava kütleleriyle birlikte orografik faktörlerin farklı yer ışıması ve fön olaylarına bağlı olarak Diyarbakır havzasında kısa mesafeler içinde farklı iklim koşullarının ortaya çıkmasına neden olduğu görülmüştür.

Anahtar Kelimeler: Diyarbakır Havzası, İklim, Uzaktan Algılama, Yeryüzü Sıcaklı̆̆ı, MODIS

Abstract: One of the factors affecting the climate on the earth is the features of rocks and ground form. The shape of the ground is an obstacle in front of the air masses and it is effective in the formation of condensation, aspect and Föhn. Lithological factors cause different rocks to have different zones of solar radiation due to their different reflectances, thus different heating of different regions of the earth. In this study, remote sensing techniques and data were used in Diyarbaktr basin in order to determine the effect of such conditions on the climate. To obtain surface temperature of the basin, day and night images for the date of 7 April 2010 (9:15 and 20:20 at local time respectively) were obtained from TERRA-MODIS satellite. Using surface temperature data, surface temperature maps are created and surface networks are registered with the model. In addition, graphs of surface temperature changes were created both through day and night data along the section lines formed by considering dominant air masses and different earth shapes. In addition, graphs of surface temperature changes were created both through day and night data along the section lines formed by considering dominant air masses and different earth shapes.

The results showed that along with lithological factors and dominant air masses; surface albedo of different orographic features, as well as Föhn event cause different climatic condition in a short distance.

Keywords: Climate, Diyarbakur Basin, Earth Temperature, MODIS, Remote Sensing 


\section{GİRiş}

Bir bölgedeki iklimi belirleyen ana unsurlar genel atmosfer dolaşımı ve hava kütleleri, iklim elemanlarının (sıcaklık, basınç, rüzgarlar, nem, yağış) özellikleri ve coğrafi faktörlerdir.

Konumu ve fiziki yapısı nedeniyle Güneydoğu Anadolu bölgesinin, özellikle Diyarbakır havzasının daha çok tropikal kökenli olan ve Arap yarımadası üzerinden bölgeye sokulan, çöl karakterli hava akımının etkili olduğu düşünülebilir. Ancak hem planeter faktörler (Genel atmosfer dolaşımı ve hava kütleleri) hem de yerel jeolojik jeomorfolojik faktörler çok farklı iklim koşullarının oluşmasına neden olur.
Türkiye'yi etkileyen hava kütlelerinin başlıcaları; maritim polar (mP), kontinental polar $(\mathrm{cP})$, maritim tropikal $(\mathrm{mT})$ ve kontinental tropikal (cP) hava kütleleridir. Bu hava kütlelerine ait cephe hareketleri karşılaşmalarına bağlı olarak farklı ve değişken hava olayları görülür (Erol, 1984:345).

Türkiye'nin kış koşullarını genel olarak, ekim ay1 sonundan başlayıp Mayıs'a kadar süren bir dönemde farklı bölgelerden Akdeniz havzasına ulaşan hava kütlelerine bağlı cephe sistemleri ve alçak basınç oluşumları yönetir.

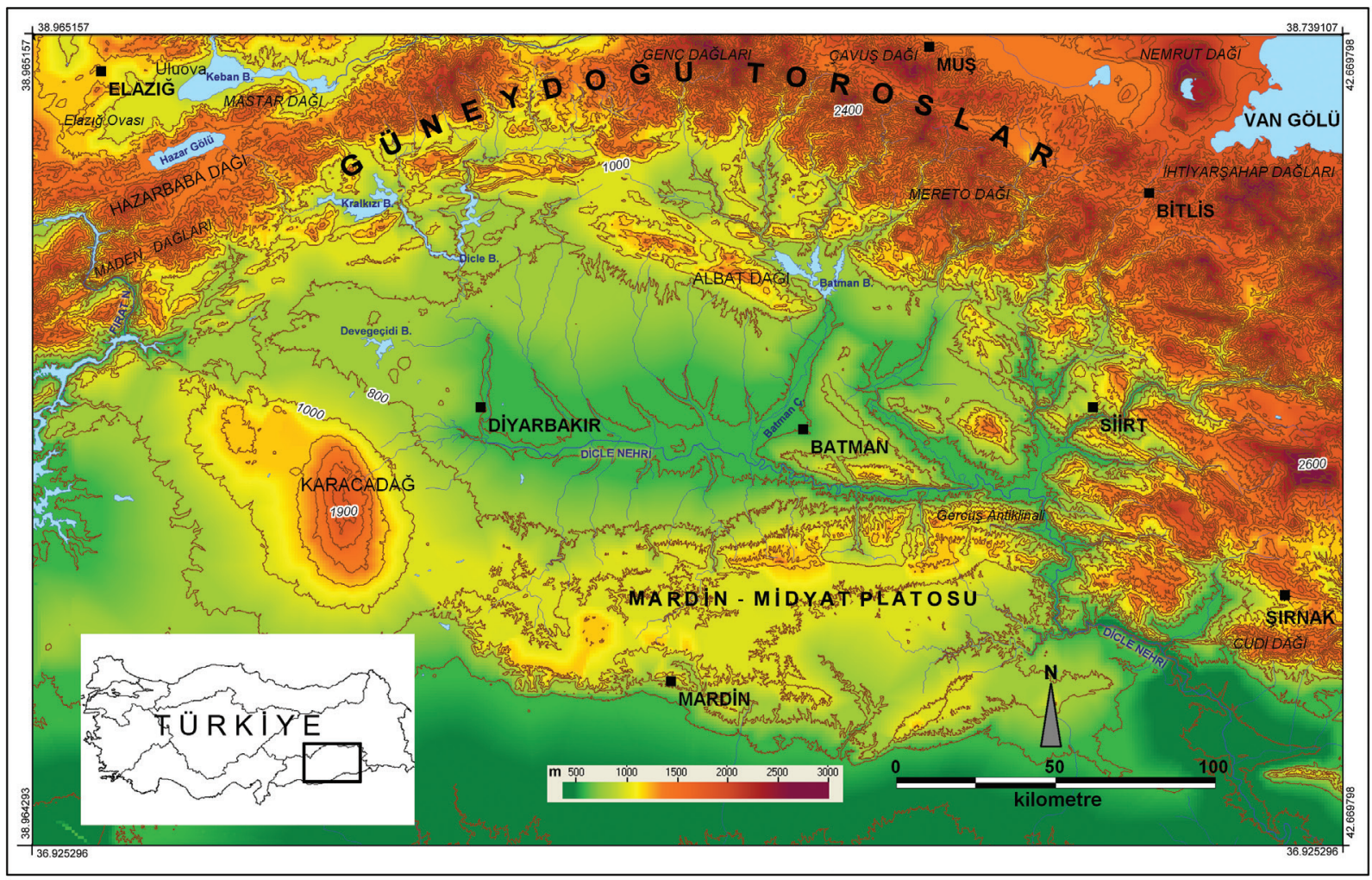

Şekil 1. Araştırma alanının lokasyon haritası.

Figure 1. Location map of the study area. 
Kuzey Ege veya Adriyatik üzerinde zaman zaman Akdeniz'e doğru akan bu hava kütlelerinin, güneyden gelen daha sicak hava tropikal hava kütleleri (mT veya cT) ile birleşmesiyle batıdan doğuya doğru depresyonların (alçak basınçların) geçişi başlar ve böylece Doğu Akdeniz havzasında baskın bir dolaşım tipi meydana gelir (Koçman, 1993).

Türkiye yağışları, kısın esas olarak bölgesel atmosferik dolaşım koşullarına ve basınç merkezlerine büyük bir bağımlılık göstermektedir. Buna karşılık yazın, yağış oluşum koşullarının yerelleştiği ve yağısın esas olarak sinoptik ya da bölgesel ölçekten daha küçük atmosferik sistemlerce, esas olarak da yerel konvektif etkinliklerce ve orografik katkıyı da içeren fiziki coğrafya koşullarınca oluşturulduğu söylenebilir (Türkeş vd. 2003).

Kuzey ve güney sektörlü farklı basınç karakterine sahip hava kütleleri arasında kalan Güneydoğu Anadolu bölgesi; genel reliyef yapısı ve deniz seviyesine göre olan yükseklik koşulları bakımından dolayı, farklı yağış koşulları göstermekle beraber, Türkiye genelinde olduğu gibi Güneydoğu Anadolu bölgesinde de yağışların büyük bir çoğunluğunun ilkbahar-kış döneminde düştüğü söylenebilir. Bu durum bölgesel ölçekli atmosferik basınç merkezleri ile ilgili bir oluşumdur.

Bölgenin sıcaklık ve yağış koşullarını belirleyen, daha çok Kafkasya (Sibirya menşeli), termik yüksek basınç ve Basra termik alçak basınç merkezleri arasındaki hava basınç sirkülâsyonlarının alansal olarak etki sahalarını genişletmeleri ile ilgilidir. Ancak yerel orografikjeomorfolojik ve litolojik koşullar havzanın iklim koşullarının belirlenmesinde etkili olmaktadırlar (Özgen, 2007:70). Bu duruma örnek olarak, kış döneminde Hazar/ Kafkasya bölgesi yüksek basınç alanından, Anadolu'ya doğrudan oluşan cP hava kütlesinin getirdiği kuru ve soğuk hava koşullarının doğu ve iç bölgelerimizdeki kadar etkili olmamakla birlikte, Güneydoğu Anadolu bölgesine kadar ulaşarak, hava sıcaklığının önemli oranda düşmesi verilebilir (Gürgen, 2002). Özellikle çevresi yükseltilerle çevrili havza tabanına çöken kuzey kökenli soğuk hava kütleleri havzada sıcaklık terselmesi olayları nedeniyle şiddetli kış soğuklarının yaşanmasına neden olmaktadır.

Yine kış ve ilkbahar hatta yaz aylarında etkili olan güney ve güneybatı sektörlü hava kütleleri havzayı Sınırlayan belirgin yükselimlerin etkisiyle fön etkisi oluşturmakta, dolayısıyla havza içinde çok yakın mesafelerde sıcaklık ve yağış koşullarında birbirine zit şartlar ortaya çıkmaktadır (Şekil 2).

Yeryüzü güneşten gelen 1şınlardan çok yeryüzünden yansiyan ve atmosferde tutulan 1şınlarla 1sınmaktadır. Dolayısıyla atmosferin nemlilik ve bulutluluk durumu ile birlikte yeryüzünün yüzey örtüsü ve özellikleri de sıcaklığın dağılışında önemli bir faktördür. Yüzey örtüsünü meydana getiren toprak ve bitki örtüsünün yanısıra yüzeydeki kayaçların da güneş ışınlarını tutma ve yansıtma kabiliyetleri (albedo) sıcaklık üzerinde oldukça belirleyicidir (GómezHeras vd. 2006; Carter ve Viles, 2004; Hapke, 1973; Ramírez ve Muñoz, 2012, Şekil 3). 


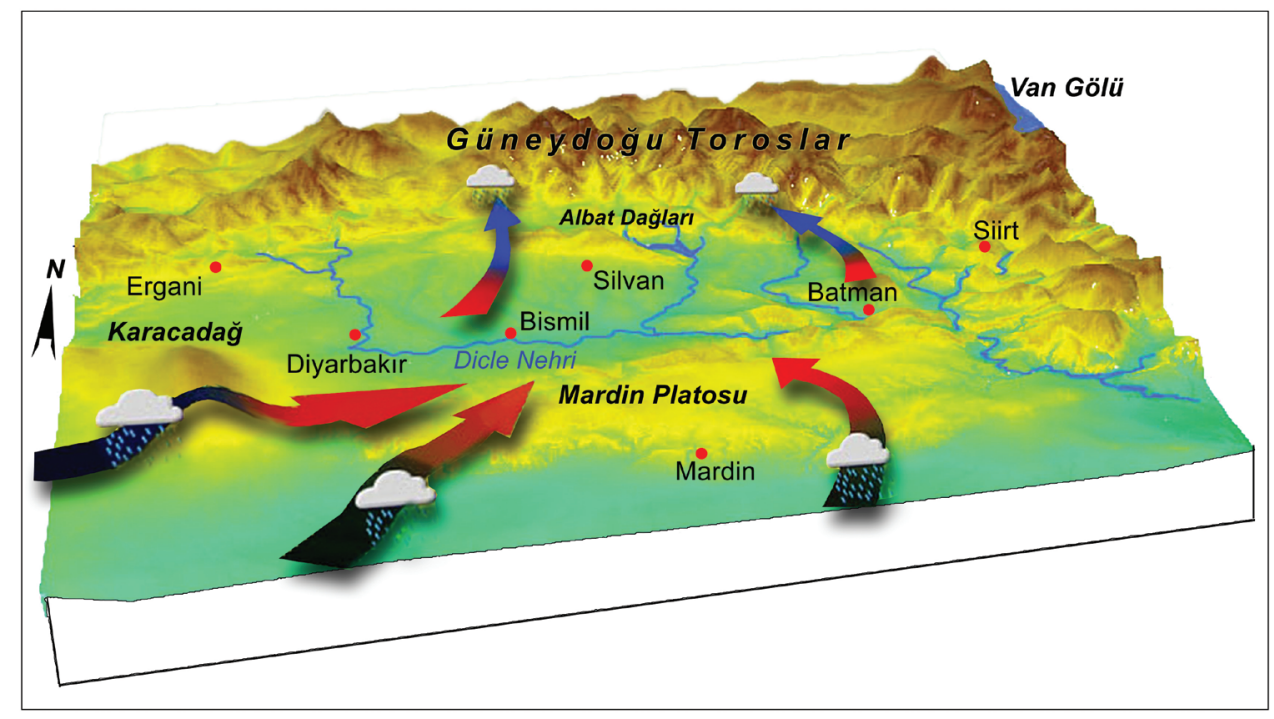

Şekil 2. Diyarbakır havzasında fön ve orografik yağış olaylarını gösteren blok diyagram.

Figure 2. Block diagram showing the events of Föhn and orographic precipitation in Diyarbakur basin.

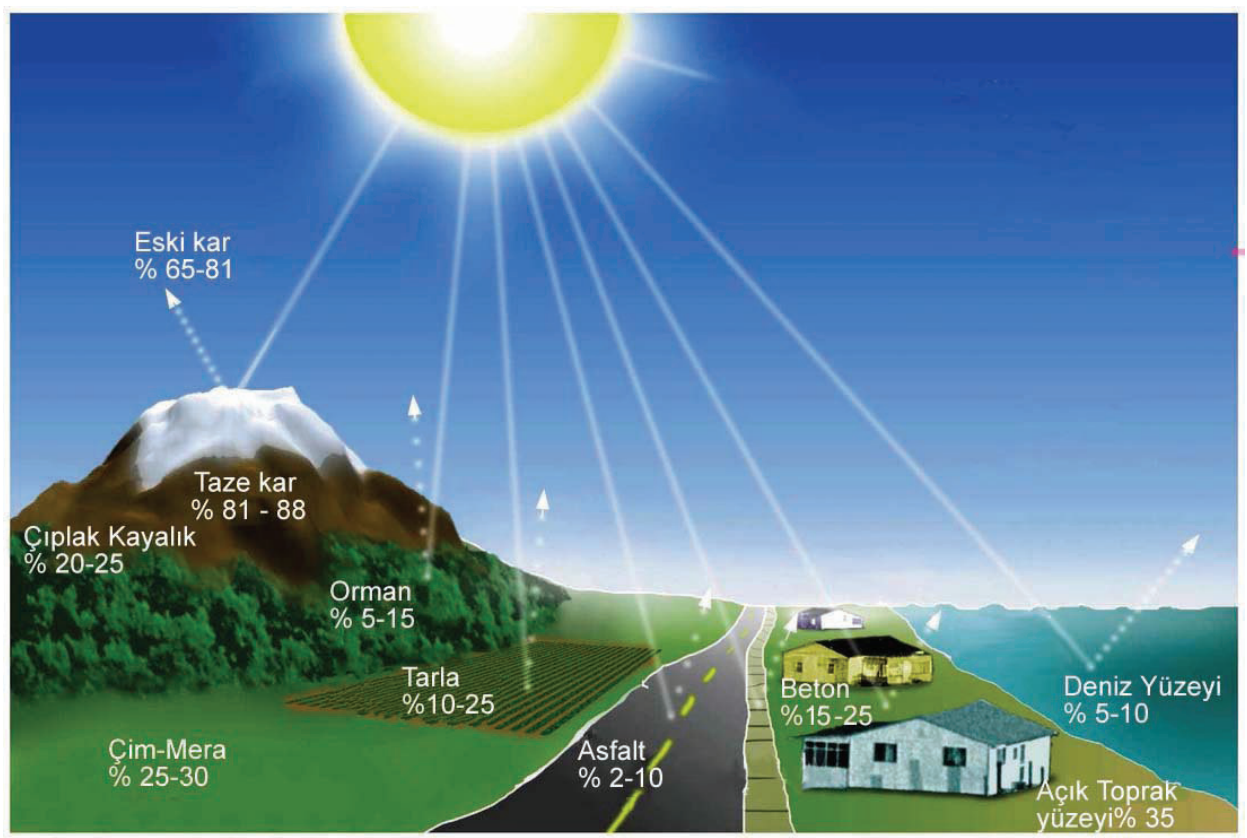

Şekil 3. Farklı yüzey ve malzemelerin tipik albedo değerleri (European Concrete Paving Association, 2009).

Figure 3. Typical albedo values of different surfaces and materials (European Concrete Paving Association, 2009).

Diyarbakır havzası farklı jeolojik zaman dilimlerinde, farklı fasiyeslerde oluşmuş çeşitli litolojilerden oluşmaktadır. Havzanın batıgüneybatısını Üst Miyosen'den Pleyistosen'e kadar sürmüş volkanizmanın eseri olan Karacadağ bazaltları örter. Doğu ve kuzeydeki antiklinallerin önemli bir bölümü Eosen'den Miyosen kadar devam eden bir zaman diliminde denizel 
ortamda oluşmuş kireçtaşlarından meydana gelmektedir. Bu antiklinalleri bölen senklinallerde ve aşındırılmış depresyonlarda ise çoğunluğu Paleozoyik ve Mesozoyik yaşlı volkano sedimanter karmaş1k birimler yüzlek vermektedir (Türkünal, 1980). Havza tabanında tersiyer gölsel karasal kumtaşı kiltaşı konglomeralar, bunların üzerinde Pliyo-Kuvaterner yaşlı karasal dolgular, vadi tabanlarında ise Kuvaterner alüvyonlar çökelmiştir (Sütçü, 2008; Şekil 4). Bu kadar çok çeşitli litolojilerden meydana gelen yüzeyin geri ışıma karakterleri farklı olacak, bu da faklı yüzey sıcaklıklarına, dolayısıyla az veya çok farklı yerel iklim koşullarına neden olacaktır.

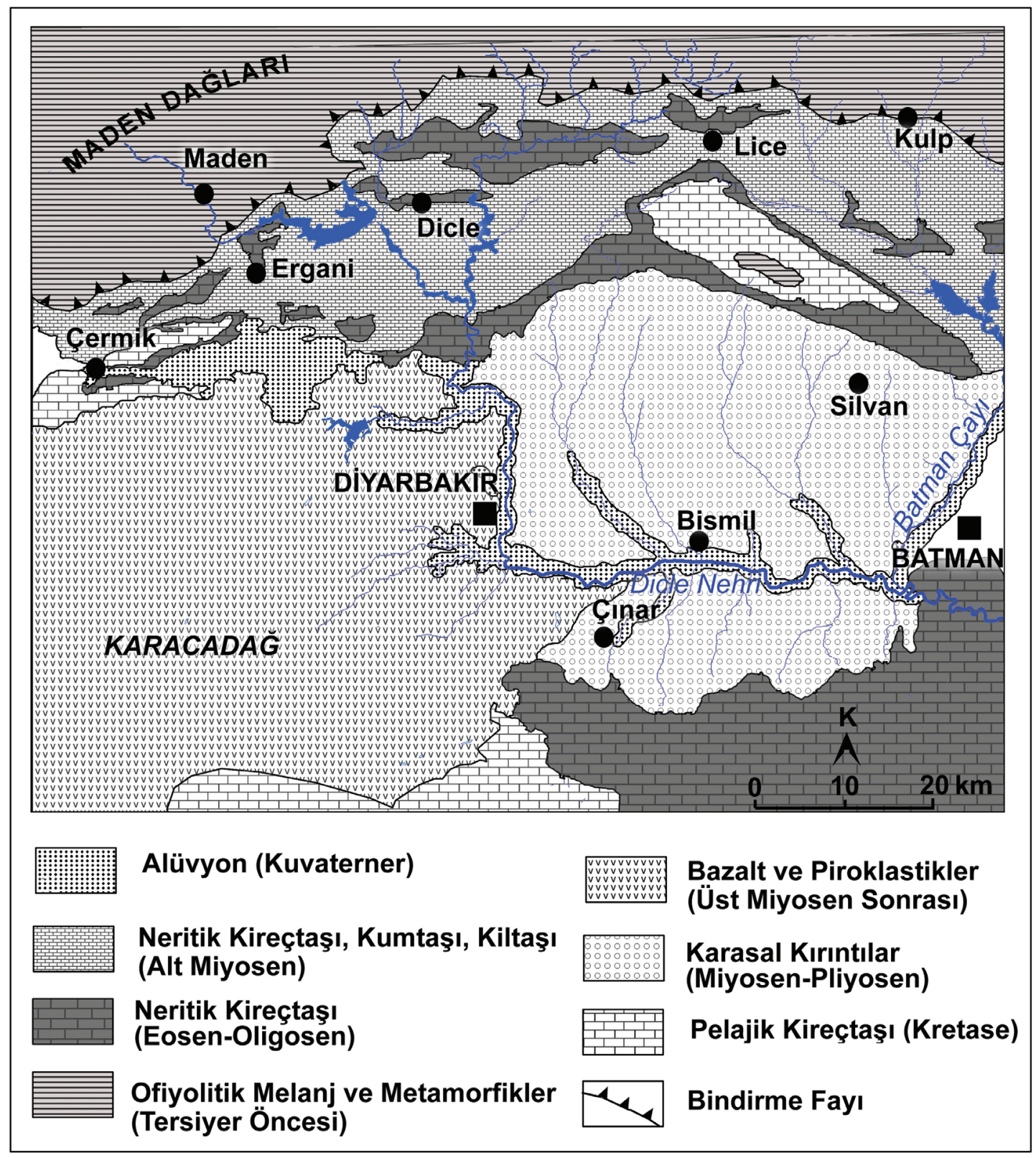

Şekil 4. Diyarbakır havzası ve çevresinin genelleştirilmiş jeoloji haritası (Sütçü, 2008'den faydalanılarak). Figure 4. Generalized geological map of the Diyarbakır basin and its surroundings (Sütçü, 2008). 


\section{MATERYAL YÖNTEM}

Belirtilen faktörlerin etkisinin araştırılması açısından Yer Yüzey Sıcaklığ 1 (LST, Land Surface Temperature), yer yüzeyi ve atmosfer arasında enerji değişimini kontrol ettiği için önemli bir parametredir.

Devlet Meteoroloji İşleri’nin kurduğu bölgesel istasyonlarda yüzey sıcaklıkları ölçülür. Ancak söz konusu istasyonlarda günün belirli saatlerinde belli bir noktanın yer yüzey sıcaklığ1 değerleri ölçülmektedir. Oysa iki meteoroloji istasyonu arasinda kilometrelerce mesafe ve sayısız topoğrafik eşik ve morfolojik değişimler söz konusudur.

Bu nedenle yer yüzey sıcaklık değerini ölçmek için daha etkili yöntem olan uzaktan algilama tekniğinden faydalanılabilir. Uydu görüntüleri, rüzgâr alanlarının belirlenmesi, bulutluluk, nem, yer yüzey ve deniz yüzey sicaklıkları, sis ve don seviyelerinin belirlenmesi, buzul alanların tespiti, yağış miktarının ölçülmesi ve vejetasyon indeksi, yüzey basıncı, toplam ozon miktarının belirlenmesinde kullanılmaktadır (Şahin 2008).

$\mathrm{Bu}$ amaçla incelemeye konu olan Diyarbakır havzasının örnek LST verilerini elde etmek için TERRA-MODIS uydusundan 7 Nisan 2010 tarihine ait yerel saat ile 09:15 ve 20:20 görüntüleri kullanılmıştır (Şekil 5 ve 6).
MODIS (Moderate Resolution Imaging Spectroradiometer-Orta Çözünürlüklü Görüntülerin Tayfsal Işınım Ölçeri), NASA tarafindan geliştirilmiş hem TERRA (1999) hem de AQUA (2002) uzay aracı üzerinde çalışan görünür 1şıklı ve kızılötesi alanlarla çalışan radyometrik cihazlardır.

MODIS, 2,330 km'lik bir görüntüleme şeridi genişliğine sahiptir ve Dünyanın her yüzeyini her iki günde bir görüntülemektedir. Algılayıc1ları 0.405 ile $14.385 \mu \mathrm{m}$ arasında 36 spektrum band ölçmekte ve $250 \mathrm{~m}, 500 \mathrm{~m}$ ve 1000 m'lik üç mekansal çözünürlükte veri toplamaktadır.

Veriler, Yer Yüzeyi Sıcaklığı (LST)'ndan, kalite değerlendirmesinden, gözlem zamanından, görüş açılarından ve yayılma (emissivity) verilerinden oluşur. Günlük Yer Yüzeyi Sıcaklığı (LST) ve yayılma verileri $1 \mathrm{~km}$ 'lik piksellerde genelleştirilmiş bölme penceresi algoritması ile ve 6 km'lik 1zgaralarda gündüz/gece algoritması ile alınd1. Gündüz/gece algoritmasında, gündüz ve gece LST'leri ve yüzeyden yayılan 1şınım, yedi TIR (Thermal Infrared, Termal Kızılötesi) bandında gece ve gündüz MODIS gözlem çiftlerinden meydana gelir. Bölünmüş pencere algoritmasında, 31 ve 32 bantlarındaki yayılma (emissivity), arazi örtü tiplerinden, atmosferik kolondaki su buharı ve alt sınır hava yüzeyi sıcaklığından optimum alınım için çekilebilir alt alanlara ayrılmıştır.

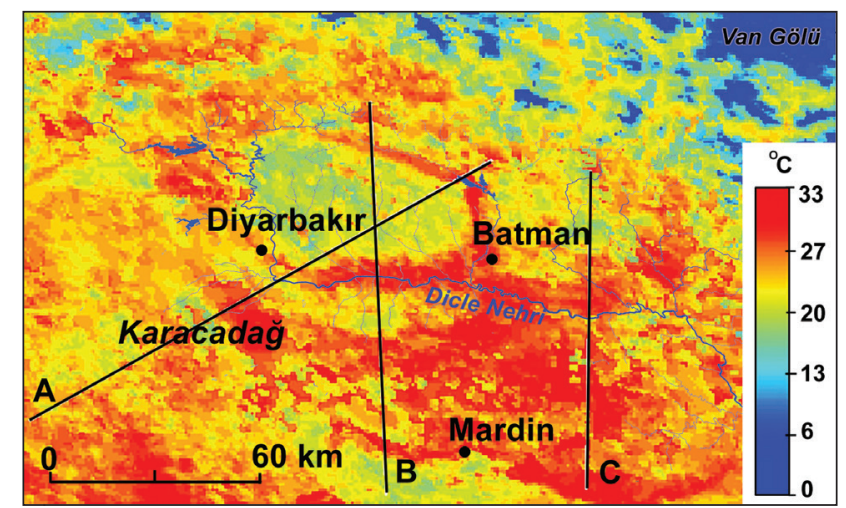

Şekil 5. TERRA-uydusu üzerindeki MODIS 7 Nisan 2010 tarihine ait yerel saat ile 09:15 görüntüsünden elde edilen Diyarbakır havzası yüzey sıcaklığı haritası.

Figure 5. Diyarbaktr basin surface temperature maps obtained from TERRA-MODIS satellite on 7 April 2010 at 09:15 am local time. 


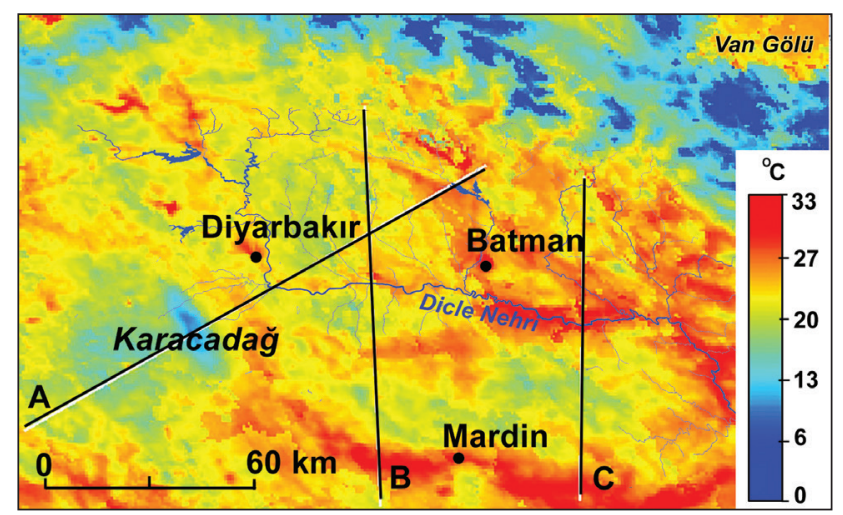

Şekil 6. TERRA-uydusu üzerindeki 7 Nisan 2010 tarihine ait yerel saat 20:20 görüntüsünden elde edilen Diyarbakır havzası yüzey sıcaklığı haritası.

Figure 6. Diyarbakur basin surface temperature maps obtained from TERRA-MODIS satellite on 7 April 2010 at 20:20 local time.
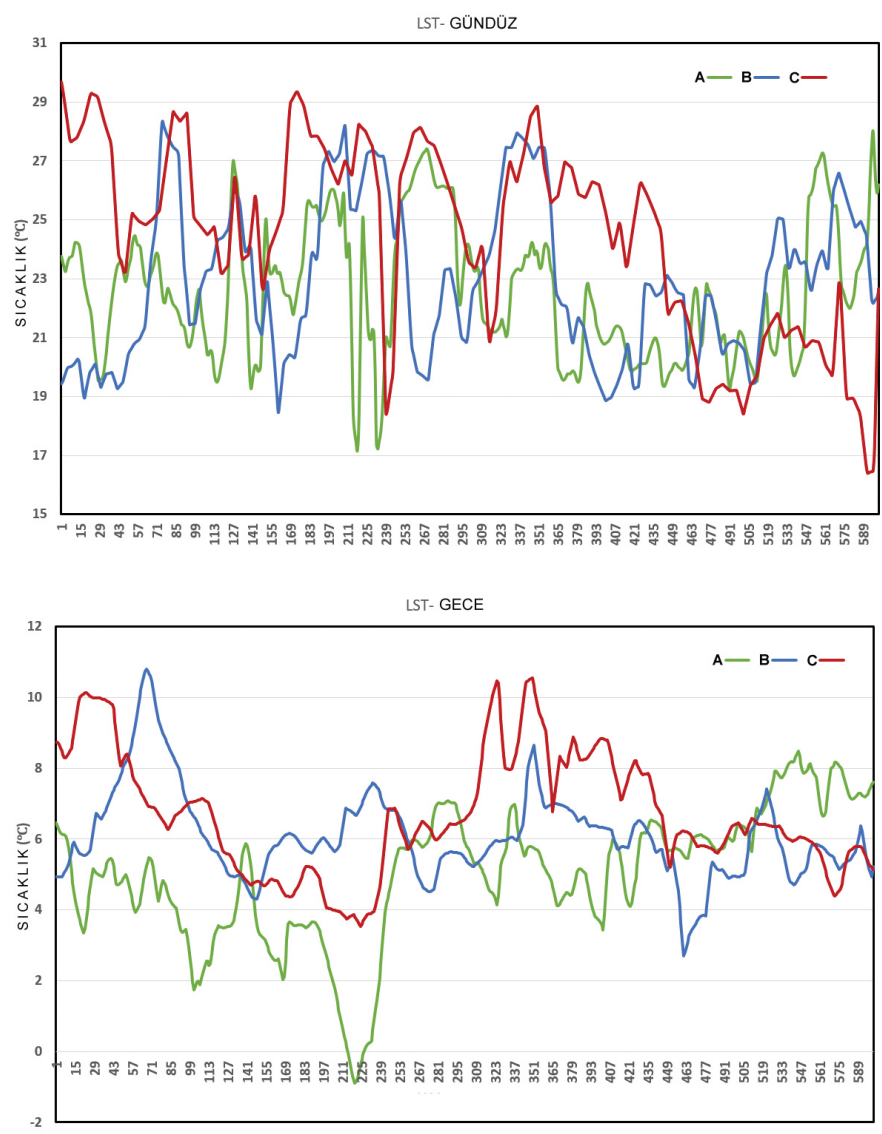

Şekil 7. Diyarbakır havzası gündüz ve gece yüzey sıcaklı̆ğ haritası üzerinde belirlenen profil hatları boyunca oluşturulan yüzey sıcaklığ değişim grafiği.

Figure 7. Temperature changes along profile lines defined on day and nigt surface temperature maps of Diyarbaklr basin. 
Elde edilen yüzey sıcaklığı haritaları üzerinde bölgeyi etkileyen baskın hava kütleleri ve farklı yeryüzü şekilleri dikkate alınarak oluşturulan kesit hatları boyunca hem gündüz hem de gece verileri üzerinden yüzey sıcaklığı değişim grafikleri oluşturulmuştur (Şekil 7).

Yüzey sıcaklığı topoğrafya ilişkilerinin bir arada gözlenebilmesi ve fiziksel arazi yüzeyini yansitabilmek amaciyla daha sonra üretilen yüzey sıcaklığ1 haritaları GETASSE30 (Global Earth Topography and Sea Surface Elevation at 30 arc second resolution) Veri Setinden türetilen sayısal yükseklik modeli DEM (Digital Elevation Model) ile TIN (Triangulated Irregular Network) Yüzey ağları modeli oluşturulmuş ve yüzey sicaklık verileriyle çakıştırılmıştır (Şekil 8 ve 9).
GETASSE30, diğer dört DEM veri kümesinin birbileşimidir.SRTM30(ShuttleRadarTopography Mission Global Coverage at 30 arc-sec) veri seti, ACE (Altimeter Corrected Elevations) veri seti ve Ortalama Deniz Yüzeyi (MSS, Mean Sea Surface) verileri EGM96 elipsoidi kaynak olarak kullanır. Elde edilen GETASSE30 veri seti, 30 Ark ( 900 m, 30 arc-sec) çözünürlükte WGS84 elipsoidi ile Dünya topografya ve deniz yüzeyi yüksekliğini temsil etmektedir. Veri setinde eksik değer bulunmamakla birlikte, kutupsal ve Antarktika kıtalarının kavşağında ACE veri kümesine özgü bazı negatif değerler (-700 m'ye kadar) mevcuttur. Tüm enlem/boylam değerleri, köşelerinden değil, bir pikselin merkezini belirtir. GETASSE30 veri kümesi birden fazla döşeme olarak düzenlenmiştir. Her katman, GETASSE30 Okuyucu kullanılarak VISAT’a aktarılabilen ilişkili dosyada saklanır.

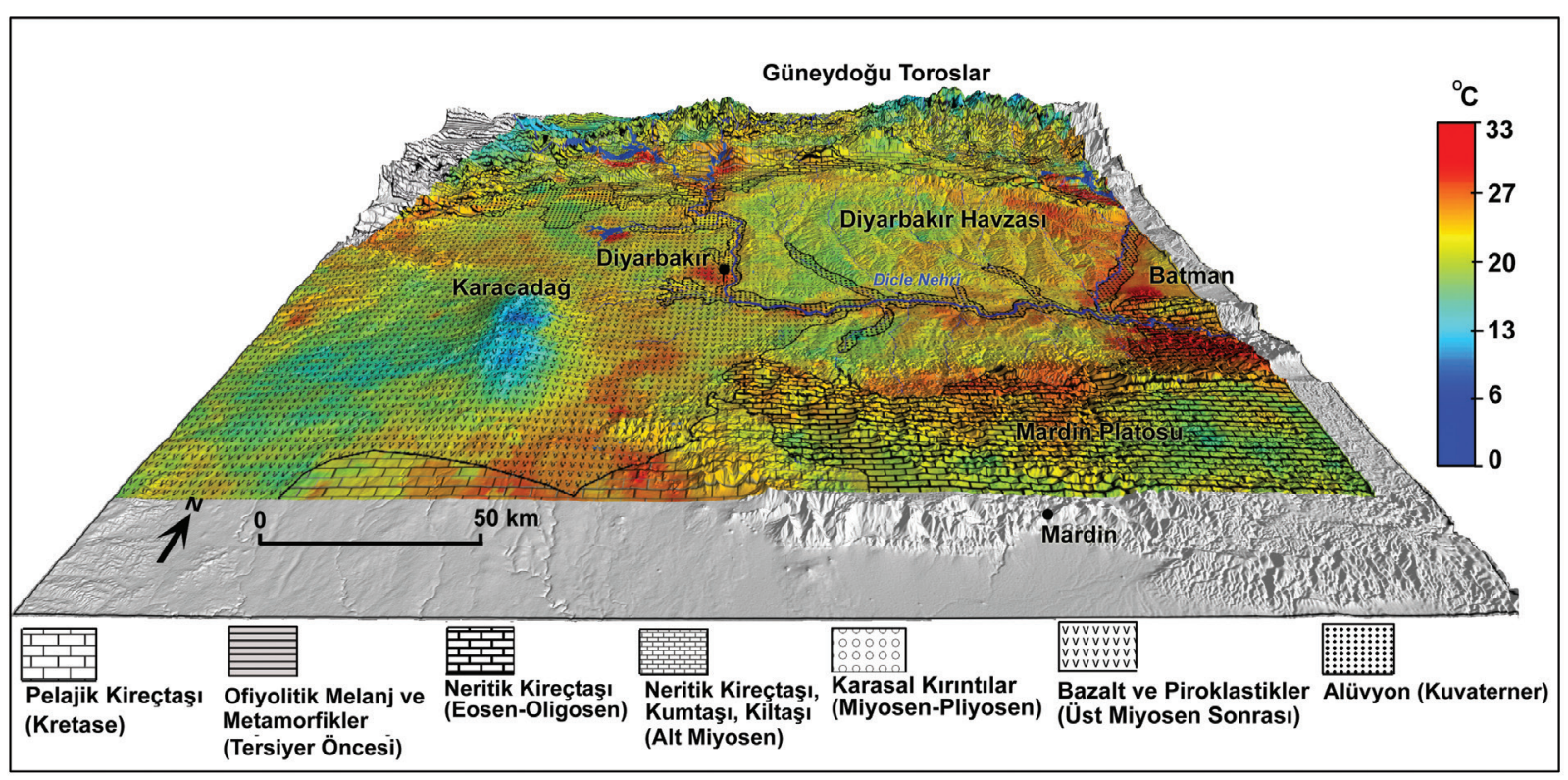

Şekil 8. Diyarbakır havzası gündüz yüzey sıcaklı̆̆ı ve litoloji haritası ile çakıştırılmış TIN (Triangulated Irregular Network) Yüzey ağları modeli.

Figure 8. TIN (Triangulated Irregular Network) surface networks model fitted with day surface temperature and lithological maps of Diyarbakı basin. 


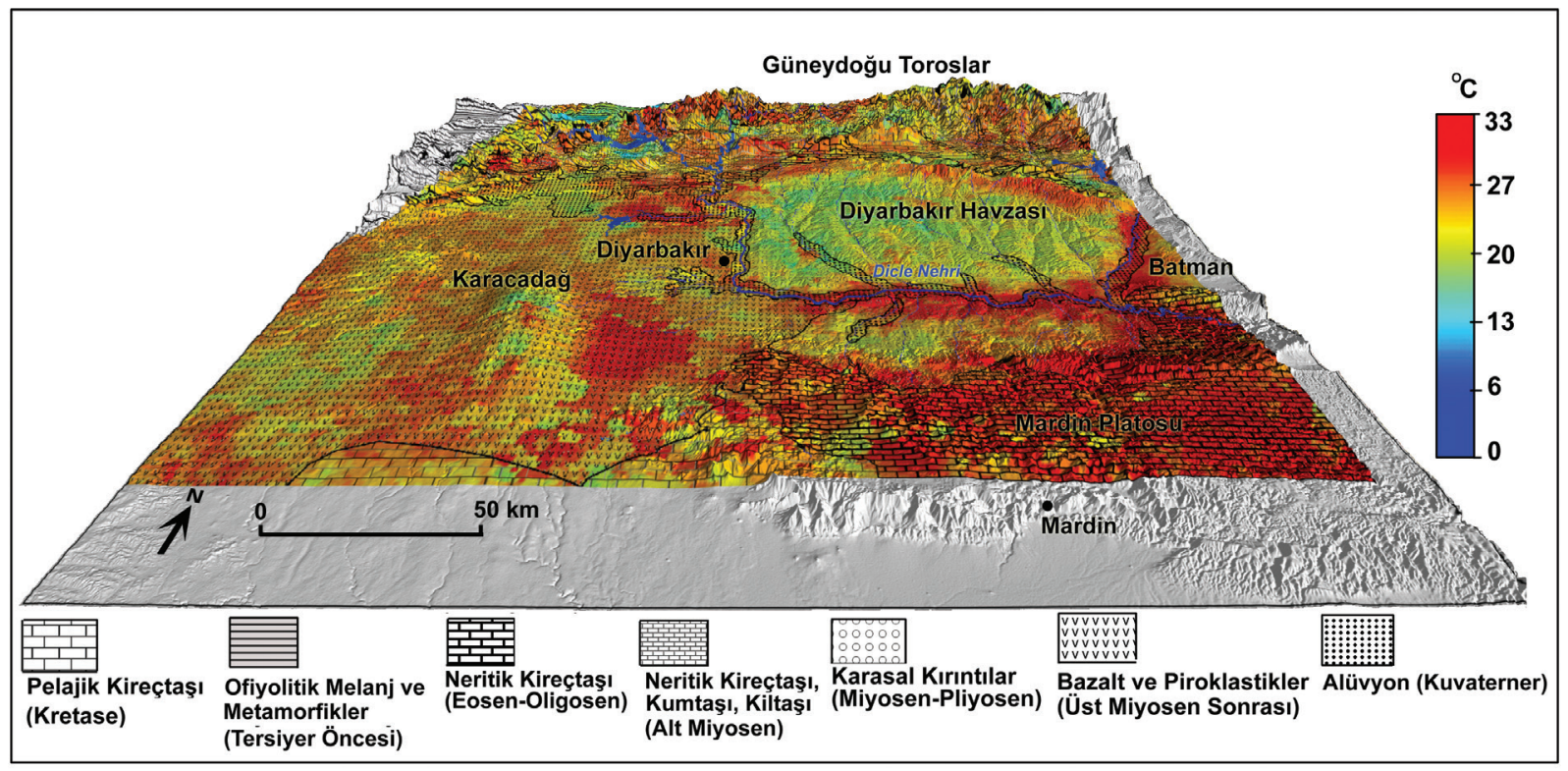

Şekil 9. Diyarbakır havzası gece yüzey sıcaklığı ve litoloji haritası ile çakıştııılmış TIN (Triangulated Irregular Network) Yüzey ağları modeli.

Figure 9. TIN (Triangulated Irregular Network) surface networks model fitted with night surface temperature and lithological maps of Diyarbakır basin.

\section{BULGULAR}

Karacadă̆ kütlesinin en sıcak yüzeyleri güneygüneybatı yamaçları olması gerekirken (bak1exposizyon etkisinden dolay1) tam aksine en sıcak yüzeyli yamaçlar kuzeydoğu yamaçlarıdır. $\mathrm{Bu}$ yamaçlarda yüzey sicaklı̆̆ $27^{\circ} \mathrm{C}-33^{\circ} \mathrm{C}$ arasındadır. $\mathrm{Bu}$ durum fön olayının açık bir kanıtıdır. Havzanın kuzeyindeki Güneydoğu Toroslar kütlesinin Albat dağlarının ve MardinMidyat platosunun güney-güneybatı yamaçları bak1 etkisinden dolayı en sıcak yüzey alanlarını oluşturmaktadır. Havzadaki en düşük yüzey sıcaklıklarıKaracadağ'ınyüksekkesimleriilekenar kıvrımlarının kuzey yamaçlarını oluşturan dar bir kesim dışında genellikle Neojen tortullarından oluşmuş havza tabanı düzlükleridir $\left(13^{\circ} \mathrm{C}-20^{\circ} \mathrm{C}\right.$ arasında). Aynı durum Kızıltepe-Derik-Viranşehir ovalarında da dikkati çekmektedir. Oysa bu alanlar gelişmiş bir toprak örtüsüyle kaplıdır. Toprak örtüsünden yoksun veya zayıf bir toprak örtüsüne sahip bazalt ve kalker litolojili alanların genellikle yüksek yüzey sıcaklıkları gösterdiğini, bu litolojiye sahip Karacadağ kuzeybatısı, Çınar Savur, Gercüş, Batman çevresinde fön olaylarının da etkisiyle yüzey sıcaklıkları daha da artmaktadır. $\mathrm{Bu}$ nedenle söz konusu alanlarda yüksek ve kavurucu yaz sıcaklıklarından dolayı kuraklık artmakta ve şiddetli tarımsal su ihtiyacı kaçınılmaz olmaktadır. Kayaç özelliklerinden dolayı bazalt ve kalker litolojisine sahip kayaçların bulunduğu alanların bitki örtüsü yönünden de zengin olduğunu belirtmek gerekir. Yükselti yanında kayaçların boşluklu çatlaklı karakteri özellikle köklerden sürgün veren meşe türlerinin sahada tutunmasına imkan sağlamaktadır. Bitki örtüsünün yansitılabilirliği/beyazlığı (albedo) düşürücü etkisi de yüzey sicaklıklarının yükselmesinde etkili olabilir.

Havzada gece gündüz yer yüzeyi sıcaklık farklarının en yüksek olduğu kesim Karacadağ ve çevresidir. Gündüz ortalama $33{ }^{\circ} \mathrm{C}$ 'yi bulan yüzey sıcaklığı gece eksi değerleri bulur. 
Günlük yüzey sıcaklık farklarının yüksek olması etkisini kayaçlardaki fiziksel ayrışmanın şiddetli olmasında, dolayısıyla toprak oluşum sürecinin hızlı seyretmesinde kendini göstermektedir.

Tabanlarında su bulunduran akarsu vadileri ve genç alüvyal sahalar nemlilik şartlarından dolayı yüzey sıcaklıklarının yüksek olduğu diğer alanlardir.

Elde edilen yüzey sıcaklığı haritaları üzerinde bölgeyi etkileyen baskın hava kütleleri ve farklı yeryüzü şekilleri dikkate alınarak oluşturulan profil hatları boyunca yüzey sıcaklığı değişim grafikleri oluşturulmuştur.

Gündüz yüzey sıcaklık profillerinde güneşe bakan güney güneybatı yamaçlar yüksek yüzey sıcaklık değerleri göstermekte ancak en yüksek değerler Karacadağ'ın ve Mardin Midyat antiklinalinin kuzey kuzeydoğu yamaçlarında ve akarsu vadilerinde görülmektedir. En düşük yüzey sıcaklık değerleri ise havza tabanında PliyoKuvaterner yüzeyleri üzerindedir.

Gece A profili oldukça dikkat çekicidir. Karacadağ kütlesinin güneybatı yamaçları boyunca yüzey sıcaklığı diğer güney ve güneybatı yamaçlarının aksine sürekli düşüş göstermekte ve Karacadağ'ın zirvesinde 1şıma (radyasyon) penceresi özelliğinden dolayı havzanın en düşük değerlerine ulaşmaktadır. Ancak kuzeybatı yamaçları boyunca yüzey sıcaklığı havza kuzeyine kadar sürekli artış eğilimi göstermektedir.

\section{SONUÇ}

Yerel coğrafi faktörler, özellikle jeoloji ve jeomorfoloji yerel iklim koşullarının oluşmasında önemli bir yere sahiptir. Bir yerin iklim özellikleri belirlenirken bakı (expozisyon), dulda yamaçlar, baskın hava hareketleri, yerel rüzgarlar, fön olayları ve yüzey örtüsünün 1şıma karakterlerinin (yer radyasyonu) iyi araştırılması gerekir. Söz konusu yeryüzü özelliklerinin iklim koşulları, özellikle sıcaklık elemanı üzerindeki etkisinin belirlenmesinde en etkili metotlardan biri de uzaktan algılama teknikleridir. Bu amaçla çok farklı yeryüzü şekillerine ve farklı fasiyeste jeolojik formasyonlara sahip Diyarbakır havzasının Nisan 2010 gece ve gündüz MODIS uydusu görüntülerinden elde edilen yeryüzü sıcaklık haritaları ve diyagramları yukarıdaki görüşü doğrular niteliktedir. Nitekim havzanın batı ve güneyini çevreleyen Karacadağ ile Mardin Midyat platosunun güneş radyasyonuna maruz kalan güney ve batı yamaçları kadar kuzey ve kuzeybatı yamaçları da hem gündüz hem de gece yüksek yüzey sıcaklık değerleri göstermektedir. $\mathrm{Bu}$ durum ilkbahar mevsiminde bölgeyi etkileyen egemen hava kütlelerinin Doğu Akdeniz kökenli olmasından dolayı gerçekleşen fön olaylarının etkisiyle olmalıdır. Nitekim sözkonusu topoğrafik eşikleri aşan hava kütleleri aksi yamaçlarda adiyabatik olarak isinmakta kurutucu ve kavurucu etki yapmaktadır. Ayrıca ayrışmış bir toprak örtüsüne sahip havza tabanının düşük albedo göstermesi gerekirken, yüzeyin 1sı kaybı nedeniyle düşük yüzey sıcaklığı değerleri göstermesi dikkat çekicidir.

\section{EXTENDED SUMMARY}

Geologic-geomorphological factors affect the climate. The shape of the ground is an obstacle in front of the air masses, and it has an effect on the formation of coagulation, exposition and Föhn events. In the geological factors, Lithology causes the solar radiation of different rocks to differently coalesce due to different albedo, thus different heating of the different regions of the earth. Both factors cause different climatic conditions to emerge in Diyarbakur basin. In this study, remote sensing techniques and data were used to determine the effect of such conditions on the climate.

For this purpose, 9:15 and 20:20 images of 7 April 2010 were used from TERRAMODIS compliance to obtain sample LST data of Diyarbakur basin which was subject to 
examination. Graphs of surface temperature over daytime and night time data were plotted along profile lines created by taking into consideration the dominant air masses and different earth shapes that are effective on the surface temperature maps.

In order to observe the surface temperature topography relations and to reflect the physical terrain surface, TIN (Triangulated Irregular Network) Surface Nets model was created with the digital elevation model (DEM) derived from the surface temperature maps GETASSE30 Data Set produced later and superimposed with surface temperature data.

According to the findings obtained, the hottest surfaces of the Karacadağ mass must be the south-southwest slopes (due to the influence of exposure), on the contrary the hottest slopes are the northeastern slopes. This is a clear proof of the Föhn phenomenon. The south and southwestern sector air masses which are effective in winter, spring and even summer make Föhn effect due to elevations that sweep the basin like a wall, so there are opposite conditions in temperature and precipitation conditions at very close distances within the basin.

The hottest surface areas due to the influence of the Albat Mountains of the Southeastern Taurus mass north of the basin and the south-southwest slopes of the Mardin-Midyat plateau.

It is interesting that low surface temperatures in the basin are basin plains which are usually composed of Neogene sediments. Basalt and limestone lithological areas are areas where surface temperatures are high due to low albedo because of their both rock properties and their richness in plant cover. Karacadağ and its surroundings are the areas where the surface temperature differences are highest at day and night. The night surface temperature reaches the lowest values of the basin due to the radiation window feature at the summit of Karacadağ.

\section{ORCID}

Sabri Karadoğan (D) https://orcid.org/0000-0002-0680-5745

M.Tahir Kavak (D) https://orcid.org/0000-0002-3059-7915

\section{DEĞIINILEN BELGELER}

Carter, N.E.A. ve Viles, H.A., 2004. Lichen hotspots: raised rock temperatures beneath Verrucaria nigrescens on limestone. Geomorphology, 62(1), 1-16.

Erol, O., 1984. Genel Klimatoloji, İstanbul Üniversitesi Yay. No: 3526, Deniz Bilimleri ve Coğrafya Enst. Yay. No: 310 , İstanbul

European Directive 2002/91/CE: "Directive on the Energy Performance of Buildings" "Energy Technology Perspectives: Scenarios \& strategy to 2050", International Energy Agency, OECD/IEA, Paris, 2010

Gómez-Heras, M., Smith, B.J. ve Fort, R., 2006. Surface temperature differences between minerals in crystalline rocks: Implications for granular disaggregation of granites through thermal fatigue. Geomorphology, 78(3), 236-249.

Gürgen, G., 2002. Güneydoğu Anadolu Bölgesinin İklimi. Dicle Üniversitesi, Ziya Gökalp Eğitim Fakültesi Yay. no: 12, Sayfa: 7-8, Diyarbakır.

Hapke, B., 1973. Darkening of silicate rock powders by solar wind sputtering. The Moon, 7(3-4), 342-355.

Koçman A., 1993. Türkiye İklimi, Ege Üniversitesi, Edebiyat Fak. Yay. No: 72, sayfa: 2, İzmir.

Özgen N., 2007. Bismil İlçesi’nin Coğrafyası. (Yayınlanmamış Yüksek Lisans Tezi). Ankara Üniversitesi Sosyal Bilimler Enstitüsü, Ankara.

Ramírez, A.Z. ve Muñoz, C.B., 2012. Albedo effect and Energy efficiency of cities. INTECH Open Access Publisher.

Şahin, M., 2008. Yer Yüzey Sicaklığı, Atmosferik Nem Açıklığı ve Yağış Miktarının Uydu Verileri Kullanılarak Belirlenmesi. Doktora Tezi, Çukurova Üniversitesi Fen Bilimleri Enstitüsü, Adana, 153s.

Sütçü, Y.V., 2008. Türkiye Jeoloji Haritaları, 1/100.000 ölçekli, No: 72 (L45 paftası), No: 73 (M44 paftası), No: 74 (M43 paftas1), No: 75 (L44 paftas1), Maden Tetkik ve Arama Genel Müdürlüğü, Ankara. 
Türkeş, M., Kutiel, H. ve Hirsch-Eshkol T. R. 2003. Türkiye'de aylık kurak ve yağışlı koşullarla ilişkili deniz seviyesi basıncı desenleri. Devlet Meteoroloji İşleri Genel Müdürlüğü Bilimsel ve Teknik Sunumlar 2002, Seminerler Dizisi 3: 5978, Ankara.
Türkünal, S., 1980. Doğu ve Güneydoğu Anadolu’nun Jeolojisi, Jeoloji Mühendisleri Odası Yayını, No: 08, ANKARA 